\title{
Prevalence of Violence in Nursing in the Czech Republic
}

\author{
Jaroslav Pekara ${ }^{1,2^{*}}$, Petr Hulinsky ${ }^{3}$, Marie Treslova ${ }^{4}$ \\ ${ }^{1}$ Medical College in Prague, Czech Republic \\ ${ }^{2}$ Prague Emergency Medical Services, Czech Republic \\ ${ }^{3}$ Ministry of Education, Yoiuth and Sports, Prague, Czech Republic \\ ${ }^{4}$ South Bohemian University in Czech Budejovice, Czech Republic
}

*Corresponding author: Jaroslav Pekara, Medical College in Prague, Czech Republic, Tel: +420-737 127 508; E-mail: pekara@vszdrav.cz

Received date: November 16, 2017; Accepted date: December 01, 2017; Published date: December 8, 2017

Copyright: (c) 2017 Pekara J, et al. This is an open-access article distributed under the terms of the Creative Commons Attribution License, which permits unrestricted use, distribution, and reproduction in any medium, provided the original author and source are credited

\begin{abstract}
Background: Violence in nursing care is a complicated and dangerous risk, especially for general nurses. The incidence of violence has been rising in the past few years. The article deals with the issue of violence during mutual contact of a patient and a nurse in the Czech Republic. Its main aim is to map violence which appears only during mutual contact between general nurses and patients. The secondary aims were to identify the most common problems in these situations and to find possibilities to solve them. The aims were tested by four goals.
\end{abstract}

Objective: To describe violence in Czech Republic in nursing and to appear conditions during mutual contact between general nurses and patients.

Methods: Data from questionnaires were available on 896 nurses from different departments of Czech Republic. Stated goals were verified by chi-squared test $(p=0.001)$.

Results: Female and male health care workers alike experience violence in providing nursing care in the Czech Republic. General Nurses in the Czech Republic are the professional group that is most exposed to verbal violence $(p>0.001)$. Violence in health care in the Czech Republic is thus mostly a problem of nursing care. The nurses with secondary education are exposed to violence more often than nurses with tertiary education $(p>0.001)$. There is possible to prepare nurses for dealing with a violent patient and prevent violence by choosing the correct style of communication. Based on these results, we created a short educational programme that provides nurses with communication skills which deescalate violence. Nurses can then practise these skills independently during contact with a violent patient. The results of quantitative research showed a lack of reporting of violent situations and poor support from the health care facilities management personnel.

Conclusion: The main recommendation for the practice is to educate future health care workers efficiently and on all levels of the education system. Violence in nursing care is a complicated and dangerous risk, especially for general nurses. We found out that female nurses are not more susceptible to violence than male health workers. We proved that general nurses face violence (verbal violence) above all other healthcare professionals in the Czech Republic, so that it is possible to approve that the violence is not a problem of the health care but above all of the nursing care.

Keywords: Nursing; Prevalence; Violence; Education

\section{Introduction}

Violence in the health care system is a complex and dangerous occupational hazard for health care staff that has increased continuously in recent years [1]. Among all occupational groups, health care workers are ranked as one of the most likely groups to experience workplace aggression [2]. Numerous studies have shown that work-related violence can negatively affect the psychological and physical wellbeing of health care staff. Consequently violence has an impact to the job motivation and the quality of the care. A next important yet often forgotten impact of work-related violence is the financial loss ensued by the health care system [3]. Czech Republic (CR) has a problem with violence in the health care area. CR lacks the support of government agencies, employers and research on the issue.
Gradually, however, efforts have begun to emerge, aiming to minimize violence in health care. In the $\mathrm{CR}$, small several projects have been undertaken to minimize violence and the experience from the projects suggests deficiencies in staff training and the importance of educating employees and trying to minimize violence in health care. The aim of this paper is to describe the results from the first survey of violence in the CR in nursing.

The researches on violence mostly focus on psychiatric hospitals and Intensive Care Units and these data are transferred to nonpsychiatry wards automatically (general wards, non-intensive wards). Likewise, the preventive and strategic arrangements are transferred from the ICU and psychiatry wards to the general wards and nonintensive wards. But the general wards are specific in a different way [1]. The violence seen most often in the general wards is based on escalated negative emotions which get out of control. Hahn et al. [4] found in a comprehensive literature review that $50 \%$ of health care 
Page 2 of 4

professionals in general hospitals have experienced verbal violence and $25 \%$ have been subjected to physical violence. In general, nurses tend to report violence more than other health care professionals; however, incident reporting of violence is not routine practice in general hospitals. Typically, violence in this setting is underreported. The true incidence of violence is unknown as indices often use different criteria for definition, and incidents are commonly considered a work-related problem). This type of violent behavior could be de-escalated by proper communication and specific approaches. The health care workers in CR are not trained and skilled enough in such approaches. This is due to the fact that the education at schools is not sufficient [5].

\section{Materials and Methods}

\section{Study design}

The main goal of this survey is to map out the violence that arises in the health care environment (in the CR) solely with the interaction of the general nurse and the patient. We find out which tip of violence dominates in healthcare in the Czech Republic, which professional group is the most threatened by violence in healthcare (reflecting gender aspects) and to illustrate the development of the problem in the Czech Republic. We were interested in:

- Are women (nurses) more susceptible to violence than male (health workers)?

- Are general nurses more confronted with verbal violence than other health workers?

- Are secondary school nurses more exposed to violence than college nurses?

\section{Collection of data}

A validated questionnaire was selected for the quantitative research tool. The questionnaire was selected on the basis of the recommendations of the International Labor Office, the International Council of Nurses, the World Health Organization and Public Services International. The WHO itself has recommended a questionnaire as a program to reduce violence at healthcare workplaces. The questionnaire is permanently available on the WHO website. The original WHO questionnaire contains 5 major categories with other subcategories and includes over 100 questions.

We started with questionnaire research through pre-research, which included the submission of 30 questionnaires to nurses from different departments (surgery, internal departments, acute outpatient departments). For the purposes of fulfilling our goal and targeting the research group, the original questionnaire had to be modified because the experience of the nurses was negative - the nurses said the questionnaire was very long and, in the end, uninteresting. More than half of the nurses did not complete the questionnaire (the reason was the time-consuming questionnaire). For these reasons, we limited the questionnaire to 30 questions. The quantitative research itself was implemented from March 2014 until December 2016 when we approached 1000 respondents. Respondents - nurses were approached in seminars and conferences focusing on the prevention of violence in contact with the patient (or his/her relatives).

\section{Statistical analysis}

All data from the questionnaire is shown in the quotation tables. Tables were developed in Microsoft Office Excel 2007. To verify the goals, we used quotation tables with different degrees of latitudes (according to the observed characteristics) and the chi-squared test for independence. We compared the calculated test statistics of our contingent tables with the critical value $\mathrm{x}^{2}$ of the corresponding degree of freedom at the significance level $p=0.001$. The chi-squared test for independence is suitable for our goals because it is used to assess the dependence of two quantitative variables measured on elements of the same selection.

\section{Results and Discussion}

The total number of returned questionnaires from the respondents was 1000 (return 100\%). However, we had to exclude 40 questionnaires for incompleteness. Since one of the goals was focused on the relationship of violence and education, we only analyzed nurses educated in secondary nursing schools and nurses educated in nursing college.

\begin{tabular}{|c|c|c|}
\hline Gender & Male & $79 \%$ \\
\hline & Female & $21 \%$ \\
\hline \multirow[t]{4}{*}{ Age } & $<20$ & $10 \%$ \\
\hline & $20-39$ & $27 \%$ \\
\hline & $40-59$ & $60 \%$ \\
\hline & $>60$ & $3 \%$ \\
\hline \multirow[t]{5}{*}{ Staff } & Nurse & $60 \%$ \\
\hline & Doctor & $10 \%$ \\
\hline & Paramedic & $17 \%$ \\
\hline & Physiotherapist & $8 \%$ \\
\hline & Security & $5 \%$ \\
\hline \multirow[t]{3}{*}{ Education level } & Secondary & $20 \%$ \\
\hline & College & $70 \%$ \\
\hline & University & $10 \%$ \\
\hline \multirow[t]{4}{*}{ Sort of care } & General & $28 \%$ \\
\hline & Surgery & $42 \%$ \\
\hline & Internal & $12 \%$ \\
\hline & Psychiatry & $8 \%$ \\
\hline
\end{tabular}

$\mathrm{N}=896(100 \%)$; general information of participants

Table 1: The total number of respondents in quantitative research.

Another 64 questionnaires were not deliberately included in the sample - they were nurses with higher professional education. The total number of respondents (Table 1) in quantitative research was 896 (100\%). There were 500 general nurses and thus formed the most numerous group of quantitative research. General Nurses worked in various departments (ambulance, bed and emergency department, medical rescue service). 


\begin{tabular}{|l|l|l|}
\hline Violence & Verbal & $71.5 \%$ \\
\hline & Physical & $18.5 \%$ \\
\hline Male & No & $10 \%$ \\
\hline & Verbal & $53.2 \%$ \\
\hline Female & Physical & $36.2 \%$ \\
\hline & Verbal & $76.4 \%$ \\
\hline Nurse & Physical & $13.4 \%$ \\
\hline & Verbal & $77.2 \%$ \\
\hline Doctor & Physical & $25.2 \%$ \\
\hline & Verbal & $65.2 \%$ \\
\hline Paramedic & Physical & $7.6 \%$ \\
\hline & Verbal & $70.9 \%$ \\
\hline Physiotherapist & Physical & $25.2 \%$ \\
\hline & Verbal & $66.7 \%$ \\
\hline Security & Physical & $3.3 \%$ \\
\hline & Verbal & $44.4 \%$ \\
\hline & Physical & $56.6 \%$ \\
\hline & & \\
\hline
\end{tabular}

Table 2: Respondents faced the verbal violence and physical violence.

\begin{tabular}{|l|l|l|}
\hline \multicolumn{3}{|c|}{ Violence } \\
\hline Nurse & Verbal & $77.20 \%$ \\
\hline & Physical & $17.60 \%$ \\
\hline Another staff & Verbal & $64.20 \%$ \\
\hline & Physical & $23 \%$ \\
\hline
\end{tabular}

Table 3: General nurses face above all other violence.

\begin{tabular}{|l|l|l|}
\hline \multicolumn{3}{|c|}{ Violence and education of nurses } \\
\hline Secondary & Verbal & $81.40 \%$ \\
\hline & Physical & $16.80 \%$ \\
\hline & No & $1.80 \%$ \\
\hline College & Verbal & $69.4 \%$ \\
\hline & Physical & $19 \%$ \\
\hline & No & $11.60 \%$ \\
\hline
\end{tabular}

Table 4: Respondent pool of nurses with secondary education violence.

We tried to prove that the violence relates to the gender of healthcare professionals. Hahn et al. [4] confirmed that generally male healthcare professionals are at a higher risk by violence not regarding the violence form (verbal or physical). Authors asked healthcare professionals in a study from Palestina [6] about violence in the last 12 months (the total number of respondents: 928, 636 nurses and 292

non-physician medical professionals; men $40.8 \%$, women $59.2 \%$ ). Hahn et al. [7] carried out their own research dealing with the issue of violence in the healthcare in Switzerland and they found out that women are at the highest risk by violence in the healthcare. 641 respondents (71.5\%) faced verbal violence in the last 12 months and 165 respondents (18.5\%) faced physical violence. 90 respondents (10\%) did not face any violence in the last 12 months. From 896 respondents (Table 2) faced the verbal violence $71.5 \%$ and to physical violence 18.5\% (male verbal: 53.2\%, male physical: 36.2\%; female verbal: $76.4 \%$,female physical: $13.4 \%$ ). In the last 12 months. We used contingencial tables (Tables 1 and 2) for our goal testing with one degree of freedom (according to characteristics pursued) and a test $\chi^{2}$ for the independence. We compared calculated statistics from our contingencial tables with a critical dividing value $\chi^{2}$ by one degree of freedom on the significance level. We did not prove significant dependence in this goal $(\mathrm{p}<0.001)$. We found out that in our study does not depend on the gender.

We tried to prove that general nurses (Table 3) face above all other healthcare professionals in the Czech Republic violence (verbal violence), so that it is possible to approve that the violence is not a problem of the health care but above all of the nursing care. Darawad et al. [8] describe the extreme frequency against nurses in Jordan (95\%; total number of respondents 447 - general nurses). Similar also Fute et al. [9] describe frequency of verbal violence (90\%) against nurses in South Ethiopia (the examination sample was formed by 660 general nurses). In the Kitaneh et al., [6] study nurses (65.8\%) faced more violence than doctors (34.2\%) the most used form was verbal violence (57\%). In our research (Table 3 ) there faced verbal violence $77.2 \%$ nurses and $17.6 \%$ to physical violence. Other non-physician medical professionals faced to verbal violence in $64.2 \%$ and to physical violence $23 \%$. On the basis of our statistic method this goal was confirmed $(\mathrm{p}>0.001)$.

We were interested in the issue if higher incidence relates with the education level of general nurses. The number of violent events decreased at the emergency ward in London thanks to more staff with higher education [10]. In our research (Table 4) faced from the respondent pool of nurses with secondary education $16.8 \%$ physical violence, $81.4 \%$ verbal violence and $1.8 \%$ no violence. From the respondent pool of nurses with higher education faced $19.0 \%$ physical violence, $69.4 \%$ verbal violence and $11.6 \%$ no violence.

From another interesting result we can note that the aacker was a man $(66 \%)$ or related to the patient $(34 \%), 91 \%$ of the respondents are convinced that every incident is preventable and $77 \%$ of the medical staff perceives violent incidents negatively.

\section{Conclusion}

The results of quantitative research showed that in our study does not depend on the gender. Female nurses are not more susceptible to violence than male health workers. We proved that general nurses face violence (verbal violence) above all other healthcare professionals in the Czech Republic, so that it is possible to approve that the violence is not a problem of the health care but above all of the nursing care. In many researches about violence in the health care area we cannot find correlation between education and prevalence of violence. In our study secondary educated nurses faced more violence that tertiary educated nurses. It seems that higher incidence of violence relates with the education level of general nurses. This study was first survey on this 
Citation: Pekara J, Hulinsky P, Treslova M (2017) Prevalence of Violence in Nursing in the Czech Republic. J Nurs Care 6: 438. doi:

topic in the Czech Republic. We will continue to monitor the issue intensively.

\section{Acknowledgement}

We would like to expend our thanks to all staff members for taking part in this research and their openness.

\section{References}

1. Beech B, Phil L (2006) Workplace violence in the health care sector: A review of staff training and integration of training evaluation models. Aggression and Violent Behaviour 11:27-43.

2. Chappell D, Vittorio DM (2006) Violence at Work 3rd edn. Geneva: International Labour Office.

3. Lanctot N, Stephane G (2014) The aftermath of workplace violence among healthcare workers: A systematic literature review of the consequences. Aggression and Violent Behavior 19: 492-501.

4. Hahn S, Zeller A, Needham I, Kok G, Dassen T, et al. (2008) Patient and visitor violence in general hospitals: A systematic review of the literature. Aggression and Violent Behavior 13: 431-441.
5. Pekara J, Trešlová M (2011) Prevention of violence in nursing. Prevence úrazů, otrav a násilí 7:187-191.

6. Kitaneh M, Motasem H (2012) Workplace violence against psychicians and nurses in Palestian public hospitals: A cross-sectional study. BMC Health Serv Res 12: 469-477.

7. Hahn S, Hantikainen V, Needham I, Kok G, Dassen T et al., (2012) Patient and visitor violence in the general hospital, occurrence, staff interventions and consequences: A cross-sectional survey. J Adv Nurs 68: 2685-2699.

8. Darawad MW, Al-Hussami M, Saleh AM, Mustafa WM, Odeh H (2015) Violence against nurses in emergency departments in Jordan: Nurses perspective. Workplace Health Saf 1: 9-17.

9. Mathewos F, Zelalem BM, Negash W, Gizachew AT (2015) High prevalence of workplace violence among nurses working at public health facilities in Southern Ethiopia. BMC Nurs 14: 9.

10. Roche M, Diers D, Duffield C, Catling-Paull C (2010) Violence toward nurses, the work environment, and patient outcomes. J Nurs Scholarsh 42: 13-22. 